\title{
Acknowledgments to the First Edition
}

The research and writing of this book would not have been possible without the kindness and generosity of a number of individuals. I greatly benefited from the research assistance of Annmarie Hunter and Emily Smurthwaite. I am most grateful for their diligence and their enthusiasm for this project from start to finish. Terrence Thorpe, another outstanding student, also read several chapters and gave valuable suggestions. Bradford Dillman, Manochehr Dorraj, Nader Entessar, Mark Gasiorowski, Nikki Keddie, and Mahmood Monshipouri kindly read all or some of the chapters and gave invaluable and insightful advice. Of course, any omissions or shortcomings remain entirely my fault. Work on chapter 8 [chapter 10 in the third edition] was partly funded by a generous grant from the College of Social and Behavioral Sciences at California State University, Northridge.

This book is the outgrowth of more than a decade of teaching and lecturing on the politics and history of the Middle East. In the process, I have learned a great deal from the innumerable students who have shared with me their insights, experiences, criticisms, and comments. Both directly and indirectly, their input is no doubt reflected here. For that, I am grateful.

Chapter 9 [chapter 8 in the third edition] is an expanded, much revised version of an article that originally appeared in Third World Quarterly, vol. 19, no. 1, 1998, pp. 63-85. I am grateful to TWQ's editor, Shahid Qadir, for permission to quote extensively from the article here.

My wife, Melisa Çanli, deserves special thanks. Over the nearly five years that it took to write this book, she put up with my many solitary hours behind the computer, my frequent mood swings, and my far-toofrequent frowns. All along, she never wavered in her loving support for my work. As I was in the final stages of preparing the book, she gave birth to our beautiful daughter, Dilara. As a meager token of my love and gratitude, I dedicate this book to them both. 
This page intentionally left blank 